\title{
4-Hydroxy-3-methyl-2(1H)-quinolone, originally discovered from a Brassicaceae plant, produced by a soil bacterium of the genus Burkholderia sp.: determination of a preferred tautomer and antioxidant activity
}

Dandan $\mathrm{Li}^{1}$, Naoya Oku${ }^{1}$, Yukiko Shinozaki ${ }^{2}$, Yoichi Kurokawa ${ }^{3}$ and Yasuhiro Igarashi ${ }^{*}$

\section{Letter}

Address:

${ }^{1}$ Biotechnology Research Center and Department of Biotechnology,

Toyama Prefectural University, 5180 Kurokawa, Imizu, Toyama

939-0398, Japan, ${ }^{2}$ National Institute of Technology, Toyama College,

13 Hongo-machi, Toyama City, Toyama 939-8630, Japan and

${ }^{3}$ Department of Bioscience and Biotechnology, Fukui Prefectural

University, Eiheiji-cho, Fukui, Japan

Email:

Yasuhiro Igarashi* - yas@pu-toyama.ac.jp

* Corresponding author

Keywords:

antioxidant; Burkholderia sp; quinolone; soil bacterium; $\mathrm{Zn}^{2+}$

enrichment culture
Beilstein J. Org. Chem. 2020, 16, 1489-1494.

doi:10.3762/bjoc.16.124

Received: 10 April 2020

Accepted: 08 June 2020

Published: 26 June 2020

Associate Editor: J. S. Dickschat

(c) 2020 Li et al.; licensee Beilstein-Institut.

License and terms: see end of document.

\begin{abstract}
4-Hydroxy-3-methyl-2(1H)-quinolone (1), a molecule known for a long time and recently discovered from a Brassicaceae plant Isatis tinctoria without providing sufficient evidence to support the structure, was isolated from a fermentation extract of Burkholderia sp. 3Y-MMP isolated from a soil by a $\mathrm{Zn}^{2+}$ enrichment culture. Detailed spectroscopic analyses by MS and NMR, combined with ${ }^{13} \mathrm{C}$ chemical shift comparison with literature values of the related compounds and a synthetic preparation of $\mathbf{1}$, allowed its first full NMR characterization and identification of 2-quinolone but not 2-quinolinol (2) as the preferred tautomer for this heterocyclic system. While the metal-chelating activity was negligible, compound $\mathbf{1}$ at $10 \mu \mathrm{M}$, a concentration lower than that in liquid production cultures, quenched hydroxy radical-induced chemiluminescence emitted by luminol by $86 \%$. Because some Burkholderia species are pathogenic to plants and animals, the above result suggests that $\mathbf{1}$ is a potential antioxidant to counteract reactive oxygen species-based immune response in the host organisms.
\end{abstract}

\section{Findings}

4-Hydroxy-2(1H)-quinolone (3) is a unique structural motif mostly found in alkaloids from rutaceous plants (family Rutaceae) [1,2]. This motif has several tautomeric forms includ-

ing 2,4-dihydroxyquinoline (4) [3-5], although which form to be taken seems not always be correctly identified in some of the studies [6-8]. Currently, 229 compounds are known to contain 
this unit as a part or a whole of the structure, among which only 12 originated from organisms other than rutaceous plants [9]. Examples from microbes include chymase inhibitors SF2809-I to VI from an actinomycete of the genus Dactylosporangium [10], a quorum sensing signaling molecule 2,4-dihydroxyquinoline (DHQ, 4) from Gram-negative bacteria Pseudomonas aeruginosa and Burkholderia thailandensis, [7], and 4-O- $\beta$-Dglucopyranosyl-2,3,4-trihydroxyquinoline (5) from an ascomycete of the genus Alternaria [8].

The genus Burkholderia sensu lato, within the class Betaproteobacteria, represents a polyphyletic group of bacteria, which undergoes reclassification into several lineages [11]. Members of this group are basically free-living aerobes inhabiting soil and freshwater, but some are also found in the tissues of animals, plants, or fungi as pathogens or beneficial symbionts [12]. Not only as the subjects of human/animal health care and plant pathology [13], but they are now gathering significant attention as an emerging source of bioactive molecules. Many new structure classes, even after being spun off as a new genus from Pseudomonas in 1992 [14], have been discovered from this group, which, along with their large genomes comparable to those of actinomycetes or myxobacteria, demonstrate a higher capacity of secondary metabolism [15].

In the course of our continuing studies on bioactive metabolites of less studied bacterial taxa [16], Burkholderia sp. 3Y-MMP, isolated from soil by an exhaustive enrichment culture under $\mathrm{Zn}^{2+}$-load, was selected for a detailed chemical study, which resulted in the isolation of 4-hydroxy-3-methyl-2(1H)quinolone (1, Figure 1). This compound was recently reported from the root of woad (Isatis tinctoria, family Brassicaceae) with no details of structure characterization [17]. Herein we describe the isolation, unequivocal structure characterization, and antioxidant activity of compound $\mathbf{1}$.

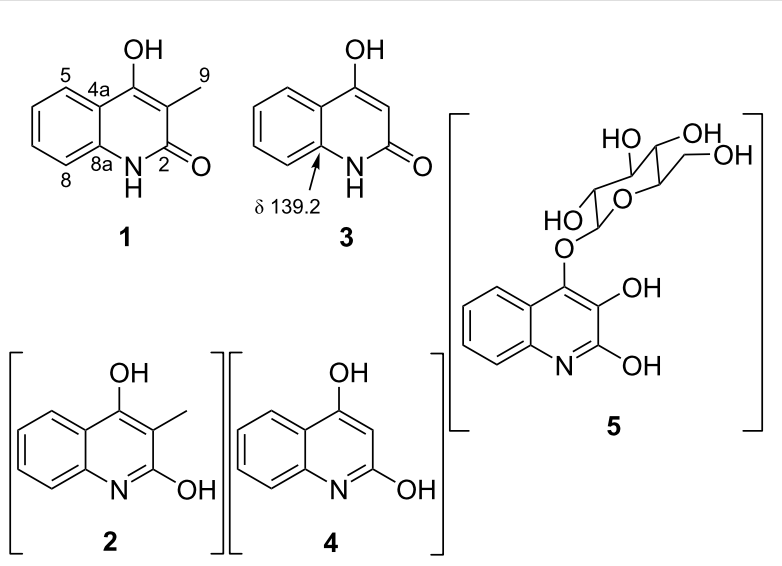

Figure 1: Structures of compounds 1-5
The producing strain 3Y-MMP was cultured in King's B medium [18] for 4 days and the production culture was extracted with $1-\mathrm{BuOH}$. The butanolic extract was partitioned between $\mathrm{CH}_{2} \mathrm{Cl}_{2}$ and $60 \% \mathrm{MeOH}$, and the latter layer was flash-chromatographed on ODS followed by reversed-phase HPLC to yield $1(5.2 \mathrm{mg})$ with sufficient purity for structure characterization.

The molecular formula of 1 was determined to be $\mathrm{C}_{10} \mathrm{H}_{9} \mathrm{NO}_{2}$ based on a sodium adduct molecular ion peak at $\mathrm{m} / z 198.0525$ observed by a HRESITOFMS measurement (calcd 198.0526). The broad IR absorption band around $3100 \mathrm{~cm}^{-1}$ and an intense peak at $1600 \mathrm{~cm}^{-1}$ indicated the existence of hydroxy and aromatic groups, respectively.

The ${ }^{1} \mathrm{H}$ and ${ }^{13} \mathrm{C}$ NMR spectra in DMSO- $d_{6}$ displayed 6 and 10 resonances, respectively, and by combining with the results of ${ }^{1} \mathrm{H},{ }^{1} \mathrm{H}$ coupling constants and COSY and HSQC spectroscopic analysis, following 8 molecular pieces were revealed: a consecutive four aromatic methines $\left(\delta_{\mathrm{C}} 129.8,122.7,121.2,115.0\right.$; $\left.\delta_{\mathrm{H}} 7.85,7.41,7.23,7.12\right)$, two heteroatom-substituted nonprotonated $\mathrm{sp}^{2}$ carbons $\left(\delta_{\mathrm{C}} 164.0\right.$ and 157.4$)$, three $\mathrm{sp}^{2}$ nonprotonated carbons $\left(\delta_{C} 137.4,115.8\right.$, and 106.9), an allylic methyl group $\left(\delta_{\mathrm{C}} 9.6 / \delta_{\mathrm{H}} 1.98 \mathrm{~s}\right)$, and a singlet exchangeable proton $\left(\delta_{\mathrm{H}} 11.30\right)$. The four methine unit $(\mathrm{C} 5-\mathrm{C} 6-\mathrm{C} 7-\mathrm{C} 8)$ was connected to the two quaternary carbons $\left(\delta_{\mathrm{C}} 137.4\right.$ and 115.8: $\mathrm{C} 8 \mathrm{a}$ and $\mathrm{C} 4 \mathrm{a}$ ) to form a disubstituted benzene ring by $\mathrm{HMBC}$ correlations H5/C8a, H6/C4a, H7/C8a, H8/C4a, and H8/C8a. On the other hand, the remaining parts were assembled into a $\mathrm{C}_{4}$ enol-amidyl or enol-imidic acyl unit based on HMBC correlations from the methyl proton $\mathrm{H}_{3} 9$ to the three nonprotonated carbons C4 ( $\delta 157.4)$, C3 ( $\delta 106.9)$, and C2 ( $\delta 164.0)$. Connection of this unit to $\mathrm{C} 4 \mathrm{a}$ of the benzene ring was implied by an $\mathrm{HMBC}$ correlation from $\mathrm{H}_{3} 9$ to $\mathrm{C} 4 \mathrm{a}$, and correlations from the exchangeable proton to $\mathrm{C} 4 \mathrm{a}$ and $\mathrm{C} 3$ supported this linkage as well as hydroxylation at the benzylic position. Finally, the chemical shift of C8a at $137.4 \mathrm{ppm}$ was in favor of $\mathrm{N}$-substitution, and comparison with the literature values from 4-methoxy1,3-dimethyl-2(1H)-quinolone (6, $\delta$ 138.4) [19], $N$-methyl-2pyridone 7 ( $\delta 139.5$ ) [20], 2,4-dimethoxy-3-methylquinoline (8, $\delta$ 147.0) [21], and 2-methoxypyridine 9 ( $\delta$ 147.2) [22] supported a 2-quinolone form 1 but not 2-quinolinol 2 (Figure 2, Table 1). The same structure was synthesized from diethyl malonate and aniline (see Supporting Information File 1 for full experimental data), which substantiated this assignment.

Although compound $\mathbf{1}$ has repeatedly been synthesized since 1921 [23] and enumerated chemical shifts for ${ }^{1} \mathrm{H}$ and ${ }^{13} \mathrm{C}$ resonances were available [24], one-on-one assignments of the resonances to each structural part have not been made until this work. In addition, HMBC correlations from the enol proton and 

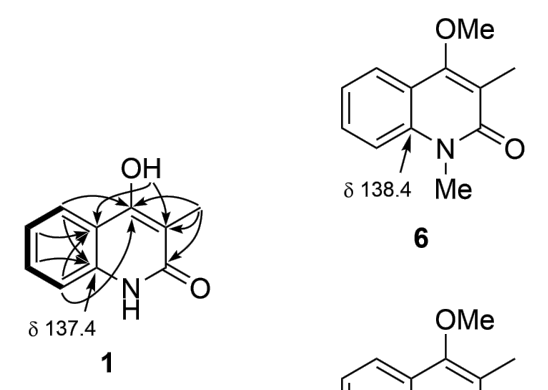<smiles>COc1cc(C)n([13CH3])c(=O)c1C</smiles><smiles>COc1nc2ccccc2c(OC)c1C</smiles>

8<smiles>CCc1cc(OC)c(C)c(OC)n1</smiles>

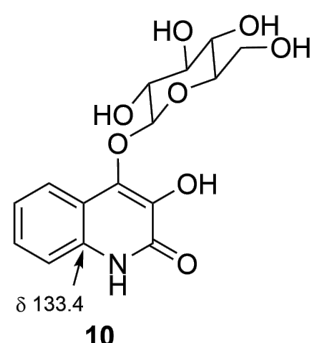

10

Figure 2: COSY-deduced spin-system (bold lines) and key HMBC correlations (arrows) for compound 1, and structures for compounds 6-10 with a ${ }^{13} \mathrm{C}$ chemical shift at the C8a position.

Table 1: ${ }^{1} \mathrm{H}(500 \mathrm{MHz})$ and ${ }^{13} \mathrm{C}(125 \mathrm{MHz})$ NMR data of compound 1 in DMSO-d 6 (297 K).

1

\begin{tabular}{lll}
\hline No. & ${ }^{13} \mathrm{C}$ & $\mathrm{H} H$ multiplicity, $(\mathrm{J}$ in $\mathrm{Hz})$, integration \\
\hline
\end{tabular}

\begin{tabular}{llll}
\hline $1^{\mathrm{a}}$ & & & \\
2 & 164.0 & & \\
3 & 106.9 & & \\
4 & 157.4 & & $3.30 \mathrm{brs}, 1 \mathrm{H}$ \\
$4-\mathrm{OH}$ & & & \\
$4 \mathrm{a}$ & 115.8 & $7.85 \mathrm{dd}(7.9,1.0), 1 \mathrm{H}$ & $4,7,8 \mathrm{a}$ \\
5 & 122.7 & $7.41 \mathrm{ddd}(7.9,7.2,0.7), 1 \mathrm{H}$ & $4 \mathrm{a}, 5,7,8,8 \mathrm{a}$ \\
6 & 121.2 & $7.23 \mathrm{~d}(8.1), 1 \mathrm{H}$ & $5,8,8 \mathrm{a}$ \\
7 & 129.8 & & $4,4 \mathrm{H}, 6,7,8 \mathrm{a}$ \\
8 & 115.0 & $1.98 \mathrm{~s}, 3 \mathrm{H}$ & $2,3,4,4 \mathrm{a}$ \\
$8 \mathrm{a}$ & 137.4 & & \\
9 & 9.6 & &
\end{tabular}

asignal for amide proton not observed.

the comparison of the chemical shift of the carbon adjacent to the nitrogen with the literature values unequivocally determined 2-quinolone to be a preferred tautomer of this heterocyclic system. The same C8a carbons of compounds $\mathbf{4}$ and $\mathbf{5}$ resonate at 139.2 [25] and $133.4 \mathrm{ppm}$ [8], respectively (Figure 1 and Figure 2), which indicates that both also exist as 2 -quinolone and hence should more precisely be called as 4-hydroxy-2(1H)-quinolone (4HQ, 3) and 4- $O$ - $\beta$-D-glucopyranosyl-3,4-dihydroxy-2-quinolone (10), respectively.

Though not alkylated, the close structural similarity to $\mathbf{3}$ suggests that $\mathbf{1}$ is also a member of the 2-alkyl-4-quinolone class signaling molecules/antibiotics known from Pseudomonas aeruginosa and some Burkholderia species [26,27]. Quinolones of this class are classified into two lineages, those with or without a 3-methyl group, and the former lineages are unique to Burkholderia producers [28]. These metabolites are shown to be biosynthesized by head-to-head condensation of anthranilate and $\beta$-ketoacylate precursors, followed by a modification at $\mathrm{C} 3$ or nitrogen by putative monooxygenases or methyltransferase [27]. Entry of malonate as the acylate precursor into this pathway is proposed to yield 3 (4 in the original literature) [29]. Thus, $\mathbf{1}$ is very likely to be biosynthesized by the same mechanism followed by additional methylation on C3.

Compound $\mathbf{1}$ is reportedly inhibitory to Mycobacterium tuberculosis $\mathrm{H} 37 \mathrm{Ra}$ at $\mathrm{IC}_{90} 6.8 \mu \mathrm{M}$ while weakly cytotoxic to MRC5 human lung-derived fibroblasts with $\mathrm{GI}_{50} 84.7 \mu \mathrm{M}$ [30]. It did 
not inhibit the production of nitric oxide in RAW 264.7 murine macrophage-like cells [31]. In our hands, 1 was inactive against any of the tested strains including Staphylococcus aureus FDA209P JC-1 (Gram-positive bacterium), Rhizobium radiobacter NBRC14554, Ralstonia solanacearum SUPP1541, Tenacibaculum maritimum NBRC16015 (Gram-negative bacteria), Candida albicans NBRC0197, and Saccharomyces cerevisiae $\mathrm{S} 100$ (yeasts).

Oxidative burst, which is a transient production of massive reactive oxygen species (ROS), is implemented in eukaryotic cells, including protists [32], as an innate immune response to deactivate foreign substances or as part of phagocytic digestion of internalized nutrients [33]. Pathogenic microbes are equipped with a multitude of strategies to circumvent host immunity [33], among which redox enzymes and antioxidants are the direct countermeasures to neutralize the toxicity of ROS [34]. Limited examples of antioxidants include catecholamine melanin from a fungus Cryptococcus neoformans [35], 1,8-dihydroxynaphthalene melanin from fungi Wangiella dermatitidis and Alternaria alternata [36], staphyloxanthin from a firmicute Staphylococcus aureus [37], vitamin $\mathrm{B}_{6}$ from fungi Cercospora nicotianae, [38] and Rhizoctonia solani [39], and a melanin-like pigment from Burkholderia cenocepacia [40].

The antioxidant activity of $\mathbf{1}$ was evaluated using the luminol chemiluminescence extinction assay $[41,42]$. This assay quantifies the presence of the most detrimental ROS, hydroxy radical $[43,44]$, as intensity of luminescence emitted by oxidation of luminol. Compound $\mathbf{1}$ at $10 \mu \mathrm{M}$, which is lower than a concentration in production liquid cultures $(15 \mu \mathrm{M})$, decreased luminescence to $14 \%$ of the control reaction (Figure 3). Because the Fenton reaction catalyzed by $\mathrm{Cu}^{2+}$ was used to generate the hydroxy radicals, entrapment of $\mathrm{Cu}^{2+}$ by $\mathbf{1}$ was initially suspected as the mechanism of chemiluminescence inhibition. However, this speculation was ruled out by a titration experi-

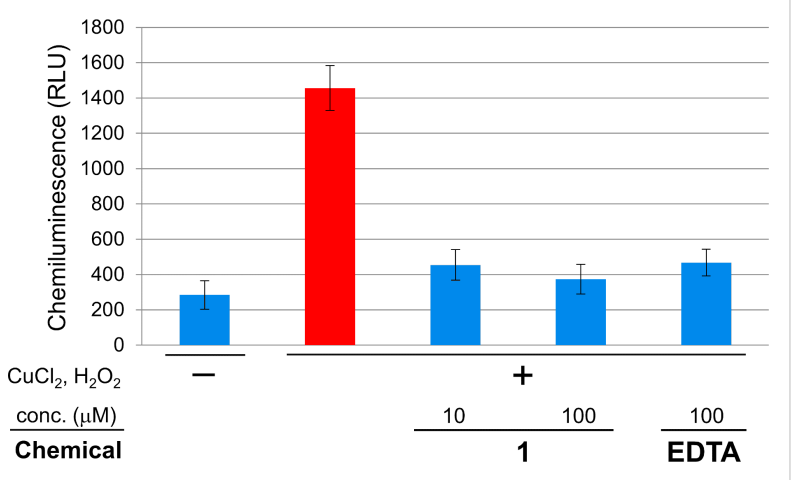

Figure 3: Extinction of luminol chemiluminescence by 1. ment using Chrome Azurol S-Fe ${ }^{3+}$ (CAS) [45], which required a 1600 times higher concentration for metal-chelation. Thus, compound 1 was found to be another example of the antioxidant from Burkholderia. Detailed studies on the antioxidation mechanism of $\mathbf{1}$ is now underway.

\section{Experimental \\ General experimental procedures}

UV and IR spectra were obtained on a Hitachi U-3210 and a Perkin Elmer Spectrum 100, respectively. NMR spectra were collected on a Bruker AVANCE 500 spectrometer in DMSO- $d_{6}$ and $\mathrm{CDCl}_{3}$ referenced at $\delta_{\mathrm{H}} / \delta_{\mathrm{C}} 2.49 / 39.8$ and 7.27/77.0, respectively. HRESITOFMS were recorded on a Bruker micrOTOF focus mass spectrometer. Chemiluminescence was measured on a Molecular Devices SpectraMax M2 microplate reader.

\section{Microorganism}

Burkholderia sp. 3Y-MMP was isolated from a soil sample collected in Toyama, central Japan, in June 2015 by a procedure similar to that described in [46]. One $\mathrm{mM}$ of $\mathrm{ZnCl}_{2}$, instead of $\mathrm{CoCl}_{2}$, was used as a selection pressure during the initial exhaustive enrichment culture stage. The $16 \mathrm{~S}$ rDNA sequence of strain 3Y-MMP was determined by a DNA analysis service (Tsuruga Bio, Toyobo Co. Ltd., Osaka, Japan) using a primer set 10F (5'-GTTTGATCCTGGCTCA-3') and 800R (5'-TACCAGGGTATCTAATCC-3'). A partial sequence with a length of $800 \mathrm{bp}$ (accession number LC508727) thus read was queried against the Basic Local Alignment Search Tool program (BLAST) available at the DNA Data Bank of Japan (DDBJ) website, which reported $99.9 \%$ homology to Burkholderia cepacia strain N1_1_43 (accession number MN691134). This strain will be deposited in NBRC once it resumes services, which is currently suspended due to a nationwide State of Emergency regarding COVID-19 declared on April 16 by the Government of Japan.

\section{Fermentation and isolation}

A cell mass of Burkholderia sp. 3Y-MMP, scraped off from an agar plate, was inoculated into $500 \mathrm{~mL} \mathrm{~K}$-flasks each containing $100 \mathrm{~mL}$ King's B medium composed of peptone 2\%, glycerin $1 \%, \mathrm{~K}_{2} \mathrm{HPO}_{4} 0.41 \%$, and $\mathrm{MgSO}_{4} \cdot 7 \mathrm{H}_{2} \mathrm{O} 0.15 \%$. The production cultures thus made were rotary shaken at $200 \mathrm{rpm}$ at $30{ }^{\circ} \mathrm{C}$ for 4 days. After fermentation, an equal amount of 1-butanol was added to each flask, shaken for additional $1 \mathrm{~h}$, and then centrifuged at $6000 \mathrm{rpm}$. The butanol layer was collected and dried in vacuo to give a solid $(2.7 \mathrm{~g})$ from a $2 \mathrm{~L}$ culture. The extract was partitioned between $60 \%$ aqueous $\mathrm{MeOH}$ and $\mathrm{CH}_{2} \mathrm{Cl}_{2}$, and the former layer was fractionated on ODS eluted sequentially with a step gradient of $\mathrm{MeCN} / 0.1 \% \mathrm{HCOOH}$ mixed in ratios of $2: 8,3: 7,4: 6,5: 5,6: 4,7: 3$, and $8: 2$, respec- 
tively. A fraction eluted by $30 \% \mathrm{MeCN}$ was evaporated to provide $69.4 \mathrm{mg}$ of a solid, which was purified by HPLC on an ODS column (Cosmosil AR-II, $1 \times 25 \mathrm{~cm}$ ) eluted with $16 \%$ MeCN containing $0.1 \% \mathrm{HCO}_{2} \mathrm{H}$ at a flow rate of $4 \mathrm{~mL} / \mathrm{min}$, which yielded $1\left(5.2 \mathrm{mg}, t_{\mathrm{R}} 31.3 \mathrm{~min}\right)$ with sufficient purity for NMR-based structure characterization.

4-Hydroxy-3-methyl-2(1H)-quinolone (1): UV (MeOH) $\lambda_{\max }$ $\mathrm{nm}(\varepsilon)$ : 312 (2300), 226 (12000); IR (ATR) $v_{\max }: 3268,3186$, 2958, 2927, 1595, 1486, 1387, 1354, 1243, 1026, 772, 761, 692, $664 \mathrm{~cm}^{-1}$; HRESITOFMS $(\mathrm{m} / \mathrm{z}):[\mathrm{M}+\mathrm{Na}]^{+}$calcd for $\mathrm{C}_{10} \mathrm{H}_{9} \mathrm{NNaO}_{2}, 198.0526$, found: $198.0525 ;{ }^{1} \mathrm{H}$ and ${ }^{13} \mathrm{C} \mathrm{NMR}$ data are shown in Table 1.

\section{Evaluation of $\mathrm{Fe}^{3+}$ binding activity}

The iron-binding activity was evaluated by the CAS assay developed by Schwyn and Neilands [45]. Compound $\mathbf{1}(2.5 \mathrm{mg})$ in DMSO $(20 \mu \mathrm{L})$ was mixed with a blue-colored CAS stock solution $(50 \mu \mathrm{L})$ and further brought up to $100 \mu \mathrm{L}$ with $\mathrm{H}_{2} \mathrm{O}$ (final concentration of 1: $160 \mathrm{mM}$ ). After $10 \mathrm{~min}$ at an ambient temperature, the solution turned orange due to the loss of $\mathrm{Fe}^{3+}$ from the indicator CAS dye, indicating positive to the iron-binding ability of $\mathbf{1}$. A prolonged reaction caused biphasic separation of the mixture.

\section{Antimicrobial assay}

The antimicrobial activity was evaluated by the method described previously [16].

\section{Antioxidant assay}

The antioxidant activity was evaluated by the method described in [41]. Briefly, luminol $(10 \mu \mathrm{M}), \mathrm{H}_{2} \mathrm{O}_{2}(1000 \mu \mathrm{M})$, and vehicle solvent with or without test compounds were mixed in $50 \mathrm{mM}$ boric acid/sodium hydroxide buffer ( $\mathrm{pH}$ 9.0). To this mixture was added $\mathrm{CuCl}_{2}(100 \mu \mathrm{M})$ to initiate the Fenton reaction, and after $5 \mathrm{~min}$ of incubation, the chemiluminescence at $500 \mathrm{~nm}$ was recorded on a microplate reader. The experiments were run in triplicate, and the mean ratio of light extinction was expressed as the potency of antioxidant activity.

\section{Supporting Information}

\section{Supporting Information File 1}

Synthetic procedure of $\mathbf{1}, \mathrm{UV}, \mathrm{IR},{ }^{1} \mathrm{H} \mathrm{NMR},{ }^{13} \mathrm{C} \mathrm{NMR}$, COSY, HSQC, HMBC spectra for natural and synthetic 1, and UV, IR, ${ }^{1} \mathrm{H}$ NMR, ${ }^{13} \mathrm{C}$ NMR spectra for synthetic intermediates.

[https://www.beilstein-journals.org/bjoc/content/ supplementary/1860-5397-16-124-S1.pdf]

\section{Acknowledgements}

We thank Prof. Yasufumi Hikichi and Dr. Ayami Kanda at Kochi University for providing $R$. solanacearum SUPP1541.

\section{Funding}

This work was supported in part by JSPS KAKENHI Grant Number $18 \mathrm{~K} 05827$ to N. O. and President's Fund Initiative at Toyama Prefectural University FY2019.

\section{ORCID ${ }^{\circledR}$ iDs}

Dandan Li - https://orcid.org/0000-0002-0384-989X

Naoya Oku - https://orcid.org/0000-0002-2171-2168

Yasuhiro Igarashi - https://orcid.org/0000-0001-5114-1389

\section{Preprint}

A non-peer-reviewed version of this article has been previously published as a preprint doi:10.3762/bxiv.2020.48.v1

\section{References}

1. Shang, X.-F.; Morris-Natschke, S. L.; Liu, Y.-Q.; Guo, X.; Xu, X.-S.; Goto, M.; Li, J.-C.; Yang, G.-Z.; Lee, K.-H. Med. Res. Rev. 2018, 38, 775-828. doi:10.1002/med.21466

2. Shang, X.-F.; Morris-Natschke, S. L.; Yang, G.-Z.; Liu, Y.-Q.; Guo, X.; Xu, X.-S.; Goto, M.; Li, J.-C.; Zhang, J.-Y.; Lee, K.-H. Med. Res. Rev. 2018, 38, 1614-1660. doi:10.1002/med.21492

3. Arndt, F.; Ergener, L.; Kutlu, O. Chem. Ber. 1953, 86, 951-957. doi:10.1002/cber.19530860806

4. Hebanowska, E.; Tempczyk, A.; Łobocki, L.; Szafranek, J.; Szafranek, A.; Urbanek, Z. H. J. Mol. Struct. 1986, 147, 351-361. doi:10.1016/0022-2860(86)80389-1

5. Luis García Ruano, J.; Pedregal, C.; Rodríguez, J. H. Heterocycles 1991, 32, 2151-2159. doi:10.3987/com-91-5823

6. Moon, B. S.; Lee, B. S.; Chi, D. Y. Bioorg. Med. Chem. 2005, 13, 4952-4959. doi:10.1016/j.bmc.2005.05.031

7. Lépine, F.; Dekimpe, V.; Lesic, B.; Milot, S.; Lesimple, A.; Mamer, O. A.; Rahme, L. G.; Déziel, E. Biol. Chem. 2007, 388, 839-845. doi:10.1515/bc.2007.100

8. Yang, X.; Yang, J. Acta Pharm. Sin. 2008, 43, 1116-1118.

9. Dictionary of Natural Product 28.2 Chemical Search. http://dnp.chemnetbase.com/faces/chemical/ChemicalSearch.xhtml (accessed Feb 27, 2020).

10. Tani, N.; Harimaya, K.; Gyobu, Y.; Sasaki, T.; Takenouchi, O.; Kawamura, T.; Kamimura, T.; Harada, T. J. Antibiot. 2004, 57, 89-96. doi:10.7164/antibiotics.57.89

11. Estrada-de los Santos, P.; Palmer, M.; Chávez-Ramírez, B.; Beukes, C.; Steenkamp, E. T.; Briscoe, L.; Khan, N.; Maluk, M.; Lafos, M.; Humm, E.; Arrabit, M.; Crook, M.; Gross, E.; Simon, M. F.; dos Reis Junior, F. B.; Whitman, W. B.; Shapiro, N.; Poole, P. S.; Hirsch, A. M.; Venter, S. N.; James, E. K. Genes 2018, 9, 389. doi:10.3390/genes9080389

12. Mannaa, M.; Park, I.; Seo, Y.-S. Int. J. Mol. Sci. 2019, 20, 121. doi:10.3390/ijms20010121

13. Depoorter, E.; Bull, M. J.; Peeters, C.; Coenye, T.; Vandamme, P.; Mahenthiralingam, E. Appl. Microbiol. Biotechnol. 2016, 100, 5215-5229. doi:10.1007/s00253-016-7520-x 
14. Yabuuchi, E.; Kosako, Y.; Oyaizu, H.; Yano, I.; Hotta, H.; Hashimoto, Y.; Ezaki, T.; Arakawa, M. Microbiol. Immunol. 1992, 36, 1251-1275. doi:10.1111/j.1348-0421.1992.tb02129.x

15. Kunakom, S.; Eustáquio, A. S. J. Nat. Prod. 2019, 82, 2018-2037. doi:10.1021/acs.jnatprod.8b01068

16. Li, D.; Oku, N.; Hasada, A.; Shimizu, M.; Igarashi, Y. Beilstein J. Org. Chem. 2018, 14, 1446-1451. doi:10.3762/bjoc.14.122

17. Zhang, D.; Shi, Y.; Li, J.; Ruan, D.; Jia, Q.; Zhu, W.; Chen, K.; Li, Y.; Wang, R. Molecules 2019, 24, 4033. doi:10.3390/molecules24224033

18. King, E. O.; Ward, M. K.; Raney, D. E. J. Lab. Clin. Med. 1954, 44, 301-307.

19. Reisch, J.; Mester, I. Arch. Pharm. (Weinheim, Ger.) 1980, 313, 751-755. doi:10.1002/ardp.19803130904

20. Still, I. W. J.; Plavac, N.; McKinnon, D. M.; Chauhan, M. S. Can. J. Chem. 1976, 54, 280-289. doi:10.1139/v76-042

21. Osborne, A. G.; Warmsley, J. F.; Dimitrova, G. T. J. Nat. Prod. 1992 , 55, 589-595. doi:10.1021/np50083a005

22. Chambers, R. D.; Parsons, M.; Sandford, G.; Skinner, C. J.; Atherton, M. J.; Moilliet, J. S. J. Chem. Soc., Perkin Trans. 1 1999, 803-810. doi:10.1039/a809838g

23. Gabriel, S.; Gerhard, W. Ber. Dtsch. Chem. Ges. B 1921, 54, 1067-1078. doi:10.1002/cber.19210540521

24. Kawada, M.; Inoue, H.; Ohba, S.; Hatano, K.; Abe, H.; Hayashi, C.; Watanabe, T.; Igarashi, M. Novel compound, production method therefor, use of said compound, and novel microorganism. PCT Int. Pat. Appl. WO2014132902 A1, Sept 4, 2014.

25. AIST Spectral Database for Organic Compounds. SDBS No. 15669. https://sdbs.db.aist.go.jp/sdbs/cgi-bin/direct_frame_top.cgi (accessed Feb 23, 2020).

26. Heeb, S.; Fletcher, M. P.; Chhabra, S. R.; Diggle, S. P.; Williams, P.; Cámara, M. FEMS Microbiol. Rev. 2011, 35, 247-274. doi:10.1111/j.1574-6976.2010.00247.x

27. Coulon, P. M. L.; Groleau, M.-C.; Déziel, E. Front. Cell. Infect. Microbiol. 2019, 9, 33. doi:10.3389/fcimb.2019.00033

28. Vial, L.; Lepine, F.; Milot, S.; Groleau, M.-C.; Dekimpe, V.; Woods, D. E.; Deziel, E. J. Bacteriol. 2008, 190, 5339-5352. doi:10.1128/jb.00400-08

29. Zhang, Y.-M.; Frank, M. W.; Zhu, K.; Mayasundari, A.; Rock, C. O. J. Biol. Chem. 2008, 283, 28788-28794. doi:10.1074/jbc.m804555200

30. de Macedo, M. B.; Kimmel, R.; Urankar, D.; Gazvoda, M.; Peixoto, A.; Cools, F.; Torfs, E.; Verschaeve, L.; Lima, E. S.; Lyčka, A.; Milićević, D.; Klásek, A.; Cos, P.; Kafka, S.; Košmrlj, J.; Cappoen, D. Eur. J. Med. Chem. 2017, 138, 491-500. doi:10.1016/j.ejmech.2017.06.061

31. Aoki, S.; Ye, Y.; Higuchi, K.; Takashima, A.; Tanaka, Y.; Kitagawa, I.; Kobayashi, M. Chem. Pharm. Bull. 2001, 49, 1372-1374. doi:10.1248/cpb.49.1372

32. Iriti, M.; Faoro, F. Mycopathologia 2007, 164, 57-64. doi:10.1007/s11046-007-9026-7

33. Siddiqui, R.; Khan, N. A. Exp. Parasitol. 2012, 130, 95-97. doi:10.1016/j.exppara.2011.11.005

34. Teng, T.; Ji, A.; Ji, X.; Li, Y. J. Immunol. Res. 2017, No. 9671604. doi:10.1155/2017/9671604

35. Jacobson, E. S.; Emery, H. S. J. Bacteriol. 1991, 173, 401-403. doi:10.1128/jb.173.1.401-403.1991

36. Jacobson, E. S.; Hove, E.; Emery, H. S. Infect. Immun. 1995, 63, 4944-4945. doi:10.1128/iai.63.12.4944-4945.1995

37. Clauditz, A.; Resch, A.; Wieland, K.-P.; Peschel, A.; Götz, F. Infect. Immun. 2006, 74, 4950-4953. doi:10.1128/iai.00204-06
38. Bilski, P.; Li, M. Y.; Ehrenshaft, M.; Daub, M. E.; Chignell, C. F. Photochem. Photobiol. 2000, 71, 129-134. doi:10.1562/0031-8655(2000)071<0129:sipvbp>2.0.co;2

39. Samsatly, J.; Chamoun, R.; Gluck-Thaler, E.; Jabaji, S. Front. Microbiol. 2016, 6, 1429. doi:10.3389/fmicb.2015.01429

40. Keith, K. E.; Killip, L.; He, P.; Moran, G. R.; Valvano, M. A. J. Bacteriol. 2007, 189, 9057-9065. doi:10.1128/jb.00436-07

41. Parejo, I.; Petrakis, C.; Kefalas, P. J. Pharmacol. Toxicol. Methods 2000, 43, 183-190. doi:10.1016/s1056-8719(00)00085-x

42. Georgetti, S. R.; Casagrande, R.; Di Mambro, V. M.; Azzolini, A. E.; Fonseca, M. J. AAPS PharmSci 2003, 5, No. 111. doi:10.1208/ps050220

43. Sakihama, Y.; Cohen, M. F.; Grace, S. C.; Yamasaki, H. Toxicology 2002, 177, 67-80. doi:10.1016/s0300-483x(02)00196-8

44. Stadtman, E. R.; Berlett, B. S. J. Biol. Chem. 1991, 266, 17201-17211.

45. Schwyn, B.; Neilands, J. B. Anal. Biochem. 1987, 160, 47-56. doi:10.1016/0003-2697(87)90612-9

46. Shinozaki, Y.; Kitamoto, H.; Sameshima-Yamashita, Y.; Kinoshita, A.; Nakajima-Kambe, T. J. Gen. Appl. Microbiol. 2019, 65, 273-276. doi:10.2323/jgam.2018.12.001

\section{License and Terms}

This is an Open Access article under the terms of the Creative Commons Attribution License (http://creativecommons.org/licenses/by/4.0). Please note that the reuse, redistribution and reproduction in particular requires that the authors and source are credited.

The license is subject to the Beilstein Journal of Organic Chemistry terms and conditions: (https://www.beilstein-journals.org/bjoc)

The definitive version of this article is the electronic one which can be found at: doi:10.3762/bjoc. 16.124 